\title{
Differences in sounds made by courting males of three closely related Lake Malawi cichlid species
}

\author{
M. C. P. Amorim*†, M. E. Knight \\ AND G. F. TuRner \\ *Unidade de Investigação em Eco-Etologia, ISPA, Rua Jardim do Tabaco 34, \\ 1149-041 Lisboa, Portugal, $\$$ School of Biological Sciences, University of \\ Southampton, SO16 7PX, U.K., §Instituto de Investigação das Pescas \\ e do Mar (INIAP/IPIMAR), 1449-006 Lisboa, Portugal and \\ \Department of Biological Sciences, University of Hull, \\ HU6 $7 R X, U . K$.
}

(Received 10 November 2003, Accepted 29 July 2004)

\begin{abstract}
Courtship sounds made by three sympatric cichlid species, Pseudotropheus zebra, P. callainos and an undescribed species known as $P$. 'zebra gold' were recorded and compared to investigate the potential role of acoustic signals in mate choice. Sounds were emitted during 'quiver' and 'circle' components of the male courtship display and consisted of rapidly repeated pulse units. Some sound variables differed significantly among species with $P$. callainos generally being separated from the other two species. This species produced sounds with higher peak frequency (for a given length) and lower number of pulses than $P$. 'zebra gold' and higher pulse durations than $P$. zebra. In addition, standard length was inversely related to peak frequency in both $P$. 'zebra gold' and $P$. callainos (this relation was not tested in $P$. zebra due to the small sample size). These differences might indicate different regimes of intraspecific sexual selection among the three species.

(C) 2004 The Fisheries Society of the British Isles

Key words: bioacoustics; Cichlidae; mate choice; Pseudotropheus; reproductive isolation; sound production.
\end{abstract}

\section{INTRODUCTION}

It is thought that there are between 450 and 650 species of cichlids in Lake Malawi. They represent one of the fastest and most spectacular examples of speciation and adaptive radiation known (Turner, 1999). The conspicuous differences in male colours of closely related species (Ribbink et al., 1983; Konings, 2002) have led to the suggestion that speciation may be driven by sexual selection, based largely on divergent female preferences for male colour (Dominey, 1984; Turner, 1994). Seehausen \& van Alphen (1998) demonstrated that assortative mating among closely related Lake Victorian cichlid species breaks down under monochromatic light, suggesting that visual cues alone may be responsible for reproductive isolation, in these species at least. Later studies

†Author to whom correspondence should be addressed. Tel.: +351 218811700; fax: +351218860954 ; email: amorim@ispa.pt 
of Malawi cichlids, however, have failed to replicate this result (Jordan et al., 2003; N.J. Barson, M.E. Knight \& G.F. Turner, unpubl. data).

Males of many cichlid species are known to make sounds during courtship (Lobel, 2001; Amorim et al., 2003). Acoustic species recognition has been demonstrated in pomacentrids (Myrberg et al., 1978; Spanier, 1979), and suggested for several other fishes, including cichlids (Lobel, 1998). Could acoustic cues be involved in species recognition among closely related species of Lake Malawi cichlids? If so, this might suggest that investigations of the establishment and maintenance of reproductive isolation among cichlids should consider acoustic as well as other non-visual cues.

To investigate interspecific differences between closely related species, courtship calls of three species of Pseudotropheus that co-occur at Nkhata Bay, on the western shore of Lake Malawi, were recorded and analysed. These are members of the most species-rich subgenus within the most species-rich group of Malawi cichlids, the mbuna, which are small largely herbivorous fishes found in shallow rocky habitats (Konings, 2002).

\section{METHODS}

\section{STUDY SPECIES}

The three focal species chosen were members of the Pseudotropheus zebra complex, now considered to belong to the subgenus Maylandia Meyer \& Foerster. The name Metriaclima Stauffer, Bowers, Kellogg \& Mckaye is sometimes used as a generic name for the group, although this is now considered a junior synonym of Maylandia (Condé \& Géry, 1999). The three taxa differ strikingly in male courtship colours but are similar in other morphological traits. Male P. zebra (Boulenger) are pale blue with black vertical bars, males of the undescribed species $P$. 'zebra gold' (Ribbink et al., 1983) have a very similar pattern of brown bars on a yellow background, while P. callainos Stauffer \& Hert males are uniform pale blue. Pseudotropheus callainos females are also distinctively coloured (blue or white), but those of $P$. zebra and $P$. 'zebra gold' are generally cryptic and easily confused, both by human observers and by courting males (Knight \& Turner, 1999). Analysis of population allele frequencies of microsatellite DNA loci indicates that these species are reproductively isolated (van Oppen et al., 1998) and they mate assortatively in the laboratory, indicating that reproductive isolation can be maintained by direct mate choice alone (Knight et al., 1998). The three species are considered to be probably at least very closely related if not sister species (Allender et al., 2003).

\section{EXPERIMENTAL PROCEDURE}

To minimize external noise, trials were conducted in a heavily insulated room. All tanks were fitted with internal power filters, $250 \mathrm{~W}$ heaters $\left(25^{\circ} \mathrm{C}\right)$ and $36 \mathrm{~W}$ overhead fluorescent lights (photoperiod of 12L:12D). Tanks were given weekly one-third water changes with tap water $(\mathrm{pH} 8 \cdot 0-8 \cdot 3)$. All fishes were fed daily on a mixture of flake and, pea and shrimp mix (Fohrman, 2002). The fishes used were all first generation laboratory stock, bred from parents collected at Nkhata Bay, Malawi $\left(11^{\circ} 36^{\prime} \mathrm{N} ; 34^{\circ} 17^{\prime} \mathrm{E}\right)$.

Three aquaria $(150 \times 45 \times 60 \mathrm{~cm})$ with a common acoustic environment (i.e. with similar background noise) were used. Each aquarium was divided into three $50 \mathrm{~cm}$ long compartments by two opaque, removable partitions. Each tank housed a single species. Seven or eight $P$. 'zebra gold', $P$. zebra or $P$. callainos females were kept permanently in each central compartment. Each end compartment held a single male. A terracotta pot provided a refuge and prospective spawning site for each male. After introduction, males were left visually isolated to acclimatize for a minimum of $24 \mathrm{~h}$. Once recording was 
complete, a male was removed, weighed (wet mass, $M$ ) and measured (standard length, $L_{\mathrm{S}}$ ), returned to a stock tank and replaced with another male of the same species. A total of 12 P. 'zebra gold', 14 P. zebra and 14 P. callainos adult males were used. Recordings for the three species were carried out within 2 months.

\section{DATA COLLECTION}

At the start of a recording period, all electrical appliances were switched off, apart from the tank lights. One of the opaque partitions was then removed, allowing one male free access to the females in the central compartment. The fishes were allowed to acclimatize to the altered conditions for $5 \mathrm{~min}$ before recording began. Sounds were

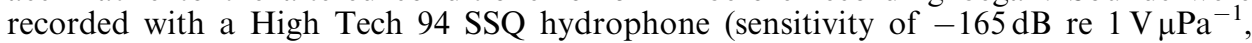
flat frequency response up to $6 \mathrm{kHz} \pm 1 \mathrm{~dB}$ ) placed near the entrance of the male's spawning site, and with a Sony TCD-D8 DAT recorder. Sound production was monitored by one researcher listening with headphones who communicated any sound production with hand signals to the other researcher who recorded behavioural data. Thus the association between sound and behaviour could be recorded. Recorded sounds could be attributed to the subject males because their intensity varied with distance from the hydrophone and were consistently associated with particular courtship displays. Male behaviour was recorded for $20 \mathrm{~min}$. Males that did not court on their first trial were re-tested up to three times before being returned to stock tanks. Female aggression or response to male courtship was also recorded.

Male courtship behaviour in these species consists of a series of distinctive and relatively invariant movements that are not always displayed in a fixed order (Baerends \& Baerends van Roon, 1950; Vodegel, 1978): quiver, male positioned laterally in front of female, body trembling; dart, male makes exaggerated but rapid $180^{\circ}$ turns displaying opposite flanks in quick succession; lead swim, male attempts to lead the female to his spawning site, swimming in front of her with exaggerated movements ('fluttering') of the caudal and dorsal fins; circle, if male is successful in attracting the female to the spawning site the pair may then follow each other around head to tail in tight circles. During 'circle'; the male again often quivers. Spawning may subsequently commence.

Aggressive behaviour typically consists of chasing (towards sub-dominant individuals), which may involve physical contact and biting, or lateral and frontal display. Lateral display is similar to the courtship quiver and frontal display involves charging head on to the opponent with all fins fully extended and flared opercula (Baerends \& Baerends van Roon, 1950; Vodegel, 1978).

\section{SOUND ANALYSIS}

Sounds were digitized at $22 \mathrm{kHz}$ (16 bit resolution) and analysed with Canary 1.2.4 for Macintosh. Only sounds that showed a clear structure and were recorded close to the hydrophone and outside the terracotta pot were considered for analysis. Typically the sounds with sufficient quality for analysis were produced at approximately one fish body length $\left(L_{\mathrm{S}}\right)$ from the hydrophone, sometimes up to two body lengths. The sounds recorded were made up of repeated pulses (see Fig. 1). The following sound variables were measured: sound duration, time elapsed from the start of the first pulse to the end of the last pulse in ms; number of pulses; pulse period, average peak to peak interval between consecutive pulse units in the entire sound in ms; pulse duration, average duration of five pulses in a sound in ms; peak frequency, frequency component with the highest energy in the entire sound in Hz. Temporal variables were measured from oscillograms. As background noise may confound the beginning and the end of pulses, the following criteria were used to measure pulse duration. Sound (pulse) onset was measured from the point of a rapid rise in positive (or negative) energy, and sound termination was determined at the zero crossing of the last cycle where sound signal decayed into the background. As it is sometimes difficult to determine sound limits perfectly, especially the sound termination since the amplitude is decaying, a further criterion was used. As the rapid oscillation in the sound waveform is much more 


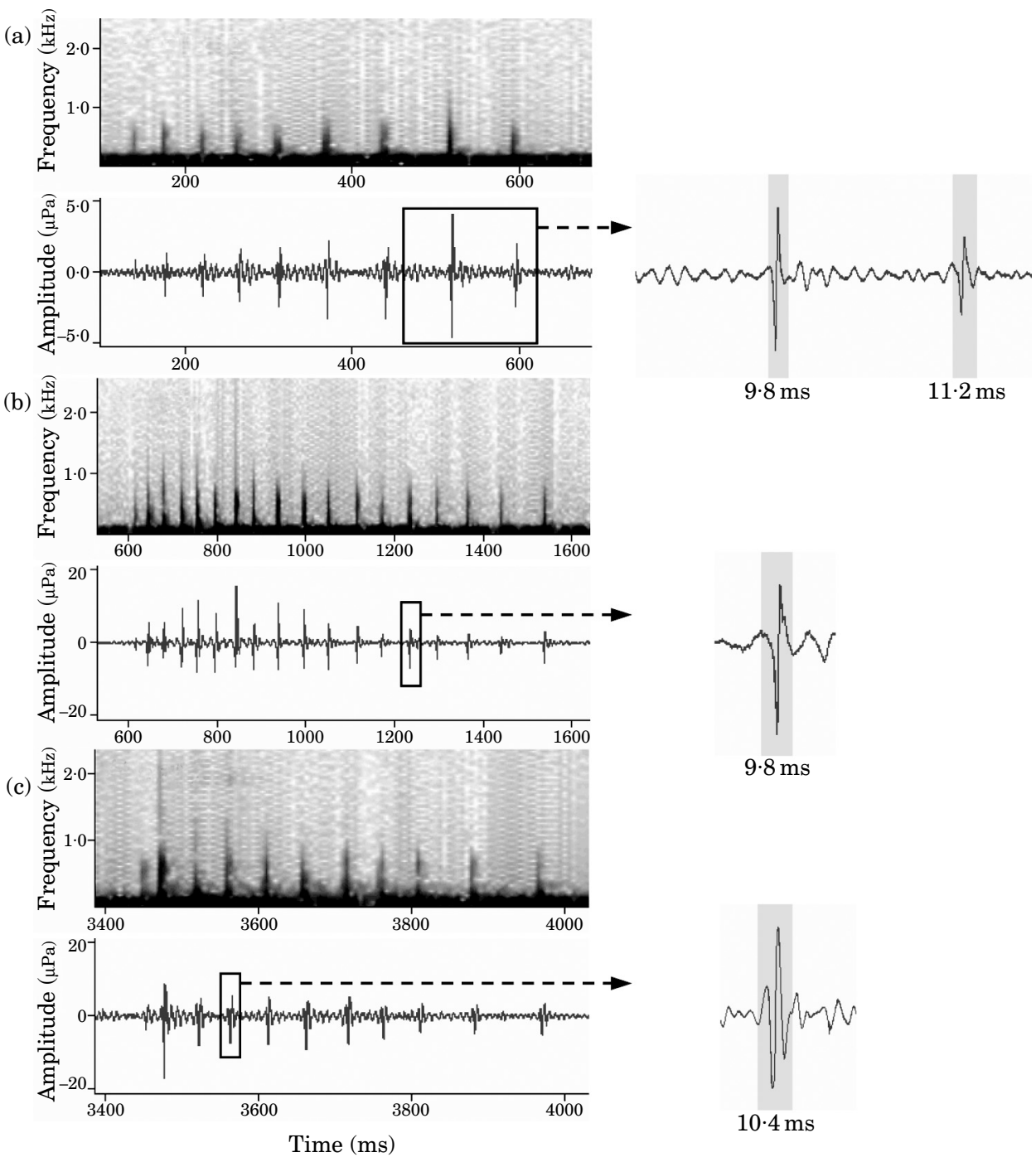

FIG. 1. Sonograms (top) and oscillograms (bottom) of typical courtship sounds produced by males of (a) Pseudotropheus 'zebra gold', (b) P. zebra and (c) P. callainos. For each species is depicted one or two pulses of sound and their durations. For $P$. 'zebra gold' a portion of the oscillograms showing two pulses is expanded to illustrate differences between the background noise and the sound pulse. Oscillograms were filtered with a (b) 60 and (a), (c) $120 \mathrm{~Hz}$ high-pass filters. The $y$-axis of the oscillograms show relative amplitudes.

homogenous than the background noise, which is usually irregular, pulse limits were considered when a more homogenous sound wave stopped and joined with irregular noise (see Fig. 1). It should be noted that the pulse structure of sounds recorded in small tanks may also be affected by reverberations in the tank (Akamatsu et al., 2002). Peak frequency was measured from the power spectra (filter bandwidth of $349 \cdot 7 \mathrm{~Hz}$ ). Highpass filters (up to $120 \mathrm{~Hz}$ but usually $60 \mathrm{~Hz}$ ) were used in oscillograms when needed to remove low-frequency background noise, but peak frequencies were always measured from unfiltered sounds. 


\section{DATA ANALYSIS}

Preliminary experiments to check for sound production by these three species produced good quality recordings for one $P$. 'zebra gold' male and two $P$. zebra males, but male size was not registered at the time. Data from these recordings are included on the general description of sounds and in the comparison among species in cases where the $L_{\mathrm{S}}$ variable was not considered important. A $\chi^{2}$-test was used to test for independence of behaviour and sound production.

Differences among species in the five sound variables measured were tested with linear mixed models (LMMs). The LMMs provide an alternative to nested ANOVA for unbalanced data sets (variable number of fish recorded within species and variable number of sounds analysed within fish in the present study) and permit the incorporation of information from continuous independent variables (fish $L_{\mathrm{S}}$ in this case). It is required that the random effects (expected response for each fish centred about the expected response for the species in this case) are normally distributed with a zero mean and a constant variance and that the within-group errors [residual deviation of each sound observation from both the fitted fixed (species) and random (individual fish) effect in this case] have a zero mean and constant variance and are independent of the random effects. Pinheiro \& Bates (2000) give an outline of the statistical principles and McRoberts et al. (1998) provide an ecological application of mixed-effects models. Exploratory analysis on the residuals of the fitted models [distribution of standardized residuals against the grouping factor (i.e. the random effect) and against fitted values, separately for each level of the classification factor (i.e. the fixed effect)] revealed that the above assumptions were adequately met (in the case of sound duration and number of pulses after logarithmic transformation), according to the inspection criteria described by Pinheiro \& Bates (2000).

In the first part of the analysis, an LMM was fitted to each sound variable using species (three level classification factor) as the fixed effect and individual fish nested within species as the random effect (nine, five and eight level grouping factor for $P$. 'zebra gold', P. zebra and P. callainos, respectively). Evidence of any differences between species was assessed by referring to the Wald statistic (a multivariate generalization of the $t$-statistic) divided by the fixed-effect d.f. to an $F$-distribution on 2 and 19 d.f. (the fixed-effect degrees of freedom and the degrees of freedom for estimating the within-group residual variance respectively). In the results, the Wald test is reported as the equivalent $F$-value on the d.f. Significant differences were investigated further by pair-wise comparisons between species using $t$-tests on 19 d.f. with Bonferroni adjustment for multiple comparisons.

The effect of fish $L_{\mathrm{S}}$ was not considered in this first analysis, as these data were not available for all fishes (particularly for $P$. zebra). Fish $L_{\mathrm{S}}$ only had a significant effect on peak frequency, so in the second part of the analysis, LMMs were fitted to the sound peak frequency observations from the species $P$. 'zebra gold' and $P$. callainos for all individuals with a known $L_{\mathrm{S}}$ (eight fish for each species). In the second analysis, the model considered the fixed effect of species, $L_{\mathrm{S}}$ and their interaction, while the random effect consisted of the individuals nested within species. The LMMs were fitted in $\mathrm{R}$ (open source software) using the library nlme (Pinheiro \& Bates, 2000).

Differences between males of the same species were tested with one-way ANOVA for each sound variable.

\section{RESULTS}

\section{SOUND PRODUCTION}

A total of 638 sounds were detected over the course of the experiment: 212 from 11 P. 'zebra gold', 152 from seven P. zebra and 274 from 10 P. callainos males. Twelve males neither attempted courtship nor produced any sound (Table I). Table I also shows information on $L_{\mathrm{S}}$ and mass as well as the number 
TABle I. Number of males of Pseudotropheus 'zebra gold', P. zebra and P. callainos that were tested, recorded, and with sounds analysed. The mean \pm S.E. (range in parentheses) number of sounds emitted per male per recording sessions and standard length of males with sounds analysed is also shown

\begin{tabular}{lccc}
\hline & $P$. 'zebra gold' & P. zebra & P. callainos \\
\hline Number of males tested & 12 & 14 & 14 \\
Number of males that produced sounds & 11 & 7 & 10 \\
Number of males with sounds analysed & 8 & 4 & 8 \\
Number of sounds per male per & $19 \cdot 25 \pm 4 \cdot 32$ & $25 \cdot 33 \pm 7 \cdot 89$ & $24 \cdot 91 \pm 7 \cdot 29$ \\
$\quad$ recording session & & & \\
Male $L_{\mathrm{S}}(\mathrm{mm})$ & $105 \cdot 3 \pm 0 \cdot 9$ & $99 \cdot 9 \pm 2 \cdot 3$ & $98 \cdot 3 \pm 2 \cdot 8$ \\
& $(100 \cdot 7-109 \cdot 6)$ & $(96 \cdot 0-106 \cdot 5)$ & $(86 \cdot 8-110 \cdot 8)$ \\
Male mass (g) & $42 \cdot 06 \pm 2 \cdot 63$ & $39 \cdot 21 \pm 3 \cdot 50$ & $32 \cdot 42 \pm 3 \cdot 08$ \\
& $(33 \cdot 41-56 \cdot 08)$ & $(31 \cdot 93-47 \cdot 24)$ & $(22 \cdot 26-46 \cdot 33)$ \\
\hline
\end{tabular}

of sounds produced per male per session by species. Sound was produced by every male that attempted to court a female. The sounds emitted by the males of these three species generally had peak frequencies $<720 \mathrm{~Hz}$, pulse durations of c. 9 to $12 \mathrm{~ms}$, pulse period of $60-70 \mathrm{~ms}$ and sound duration varying between 500 and $700 \mathrm{~ms}$ (Table II and Fig. 2). Example sonograms and oscillograms of sounds produced by each species are shown in Fig. 1.

\section{ASSOCIATION WITH BEHAVIOUR}

Courtship behaviour and sound production were significantly related $\left(\chi^{2}\right.$, d.f. $\left.=4, P<0 \cdot 001\right)$; the great majority of sounds being produced during the male 'quiver' and 'circling' displays (Table III). Sound production was also detected on one occasion while a P. zebra female performed a lateral display to a second female revealing that sound production is not restricted to males in this species.

\section{COMPARISON AMONG SPECIES}

Variation within each sound variable was generally similar across species (Fig. 2) and, with few exceptions, observations within species were symmetrically distributed about the mean (in the case of sound duration and number of pulses after $\ln$ transformation). None of the five sound variables differed significantly among males of the same species (one-way ANOVA, $P>0.05$ ). The results of the LMMs showed significant differences among species in pulse duration (Wald test, d.f. $=2$ and $19, P=0.021$ ) and peak frequency (Wald test, d.f. $=2$ and 19, $P=0.004)$. Pair-wise comparisons ( $t$-tests after Bonferroni correction for multiple comparisons), however, demonstrated that for both sound variables only one comparison between species was significant at the 5\% level. Pseudotropheus callainos was the species most clearly distinguished based on sound properties, having a significantly higher peak frequency than $P$. 'zebra gold' and a significantly higher pulse duration than $P$. zebra. 


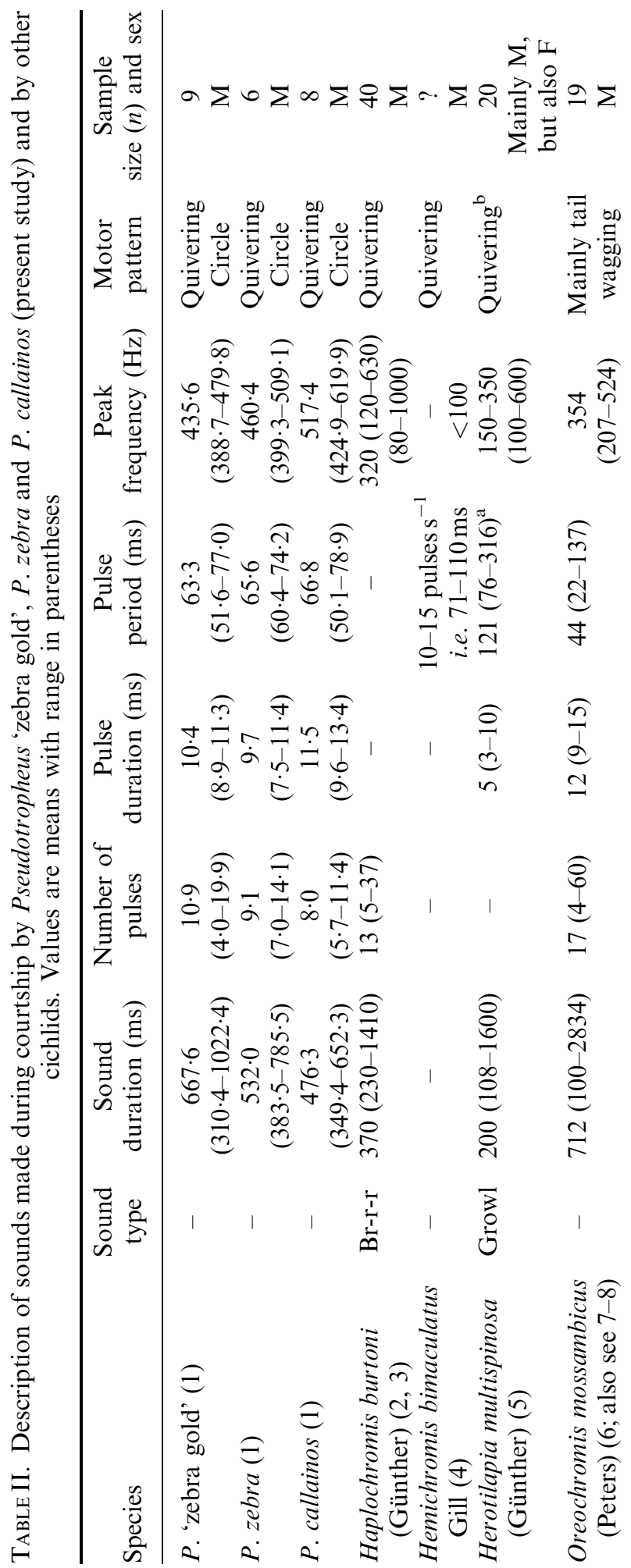




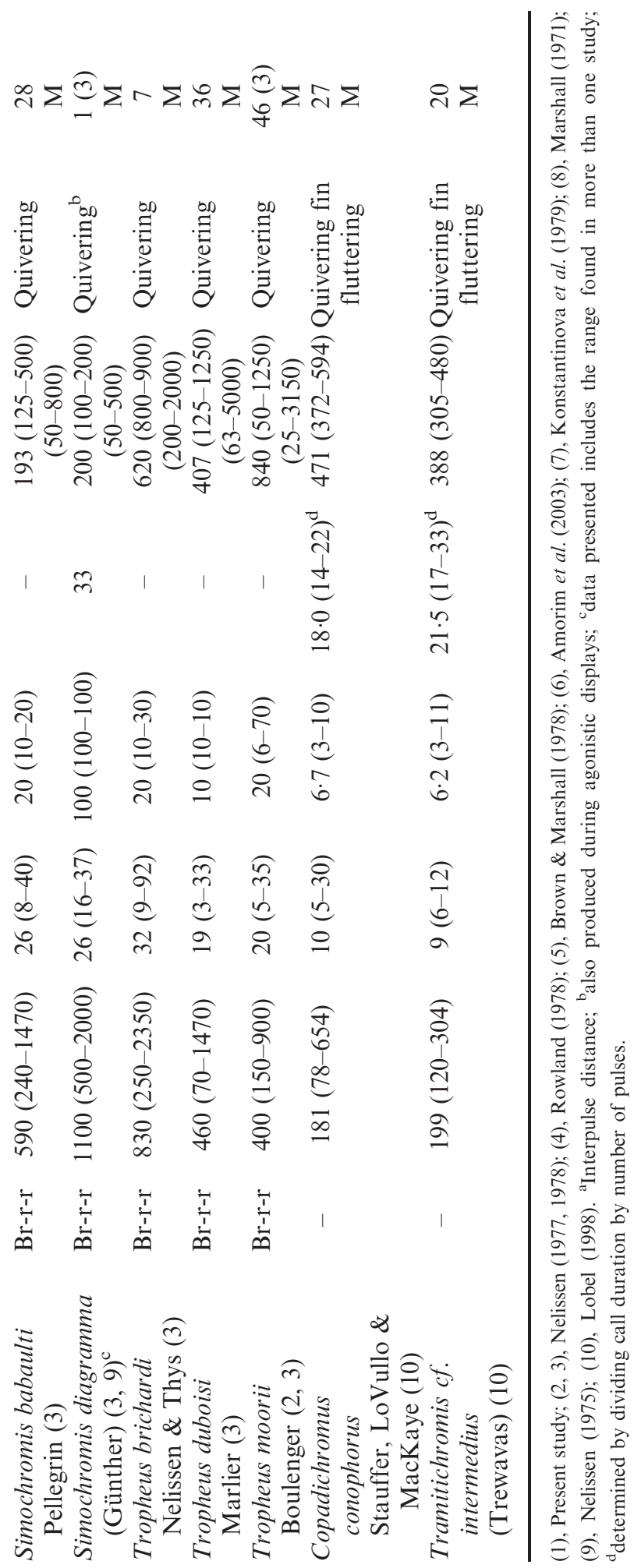



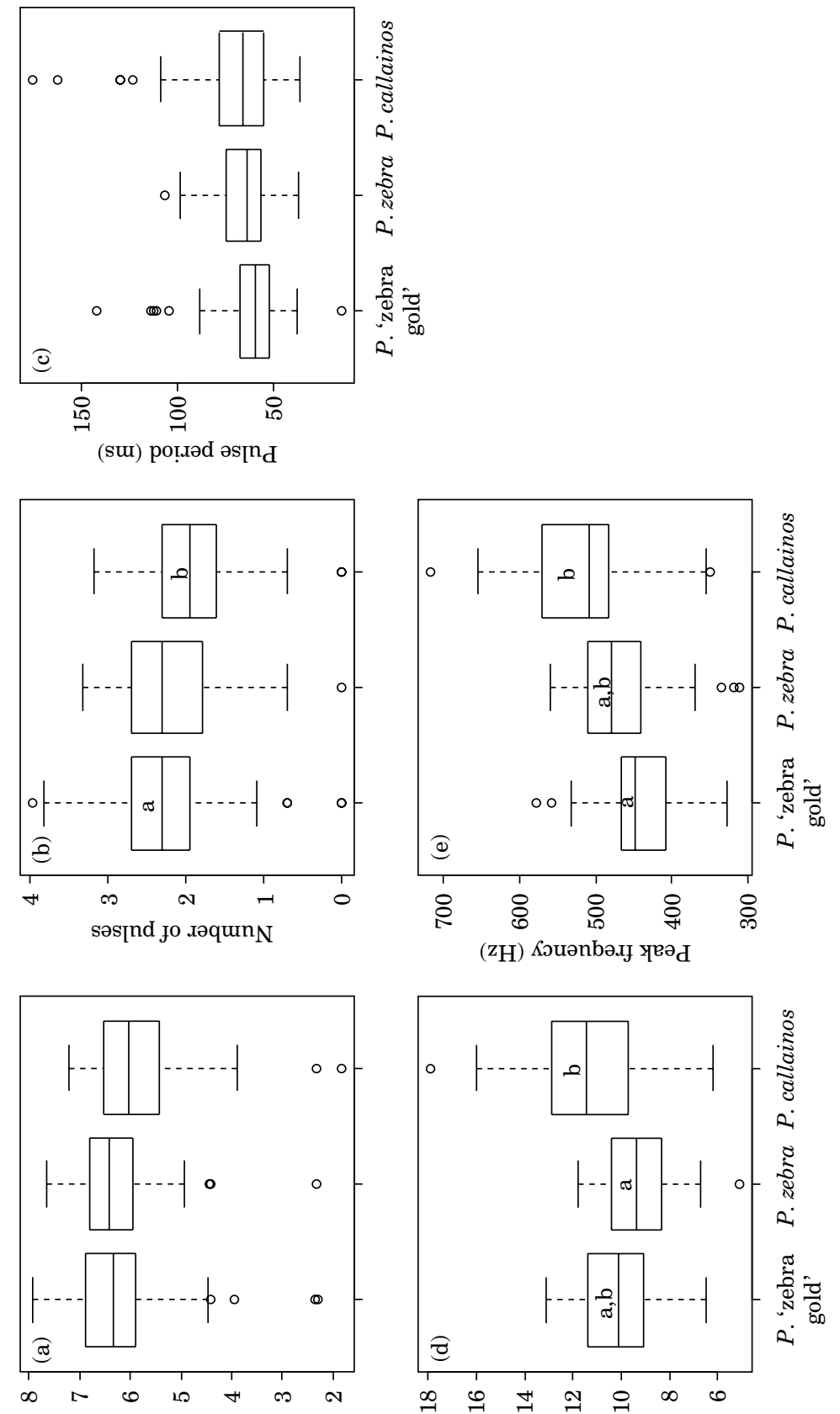

(su) uọ̣p.xnp punos

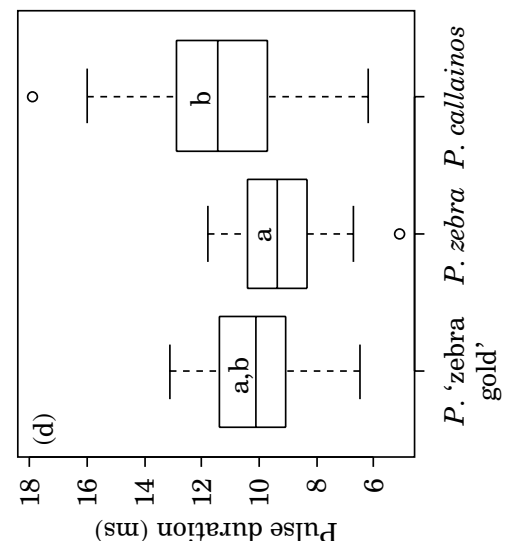

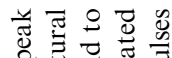

(2)

चี

으을

đত

0 0 苛

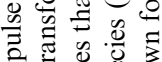

है

రే

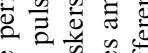

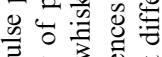

ڤ.

อ

记主泀

कृ 预 的

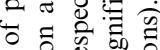

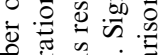

节苛离言 记泀

อิ

요융

宅 论

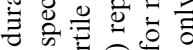

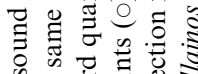

क

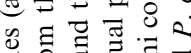

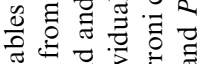

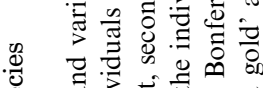

总

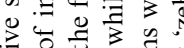

¿ 0 o

Ð

ธิ

¿ స

苋

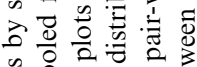

ڤ :

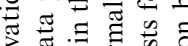

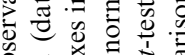

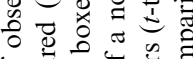

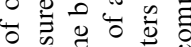

‡Е

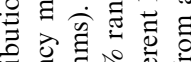

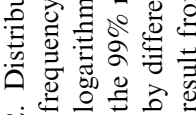

㭊 
TABLE III. Sound production and associated male behaviour (Q, quiver; LS, lead swim; D, dart; C, circle; Ch, chase; none, sound produced with no obvious associated behaviour) in Pseudotropheus 'zebra gold', P. zebra and P. callainos $(n=4478)$

\begin{tabular}{|c|c|c|c|c|c|c|c|c|c|c|c|c|c|c|c|}
\hline & $\mathrm{Q}^{*}$ & $\mathrm{Q}$ & $\% \mathrm{Q}^{* *}$ & $\mathrm{LS}^{*}$ & LS & $\%$ LS** & $D^{*}$ & $\mathrm{D}$ & $\% \mathrm{D}^{* *}$ & $\mathrm{C}^{*} \mathrm{C}$ & $\% \mathrm{C}^{* *}$ & $\mathrm{Ch}^{*}$ & $\mathrm{Ch}$ & $\% \mathrm{Ch}^{* *}$ & *none \\
\hline $\begin{array}{l}P . \text { 'zebra } \\
\text { gold' }\end{array}$ & 185 & 106 & $63 \cdot 6$ & 7 & 191 & $3 \cdot 5$ & 0 & 246 & 0 & 1043 & $3 \quad 18 \cdot 8$ & 0 & 783 & 0 & 10 \\
\hline P. zebra & 119 & 35 & $77 \cdot 3$ & 3 & 96 & $3 \cdot 0$ & 0 & 114 & 0 & 1419 & $42 \cdot 4$ & 0 & 348 & 0 & 16 \\
\hline P. callainos & 235 & 38 & $86 \cdot 1$ & 20 & 358 & $5 \cdot 3$ & 7 & 205 & $3 \cdot 3$ & 330 & $9 \cdot 1$ & 1 & 1262 & $0 \cdot 1$ & 8 \\
\hline
\end{tabular}

*, Sound produced simultaneously, otherwise behaviour recorded but no associated sound detected.

**, Proportion of the total number of any behaviour observed for each species where sounds were simultaneously recorded.

Although the comparisons among species were non-significant for the other three sound variables (Wald test, d.f. $=2$ and $19, P=0.229$ for sound duration; $P=0.090$ for number of pulses; $P=0.268$ for pulse period), there are some indications that $P$. callainos generally produced sounds of lower duration and with a fewer number of pulses (Fig. 2). Repeating the analysis only for $P$. 'zebra gold' and $P$. callainos (the two species with higher number of observations) led to a significant difference in the number of pulses between the two species (Wald test, d.f. $=1$ and $15, P=0.046$ ) but not in sound duration. If $P$. callainos is compared with $P$. 'zebra gold' and $P$. zebra (which behave in a similar fashion for both sound duration and number of pulses), however, differences in the number of pulses become more evident (Wald test, d.f. $=1$ and 20, $P=0.021$ ) and marginally non-significant for sound duration (Wald test, d.f. $=1$ and 20, $P=0 \cdot 083$ ). It is therefore likely that significant differences among species may also exist in other sound variables (in particular in sound duration and perhaps pulse period), but there is insufficient power to detect them in the present analysis (where sounds from only four $P$. zebra were used).

The above analyses did not consider the effect of fish $L_{\mathrm{S}}$ on the sound variables. Spearman rank correlations were calculated between mean sound variables and $L_{\mathrm{S}}$ for $P$. 'zebra gold' and $P$. callainos. Despite the small sample size $(n=8)$, the results indicated a highly significant negative correlation between peak frequency and $P$. callainos $L_{\mathrm{S}}(r=-0.90, n=8, P=0.002)$. Based on the above results, the LMM for peak frequency was repeated considering only $P$. callainos and $P$. 'zebra gold' and including the effect of $L_{\mathrm{S}}$ and its interaction with species. The exclusion of $P$. zebra and the inclusion of $L_{\mathrm{S}}$ as an explanatory variable did not alter the previous results, leading to the accentuation of the differences in peak frequency between the two species (Wald test, d.f. $=1$ and $12, P<0.001)$ and indicating a highly significant negative effect of $L_{\mathrm{S}}$ (Wald test, d.f. $=1$ and $12, P=0.009$ ) that was common in the two species (i.e. non-significant interaction term: Wald test, d.f. $=1$ and $12, P=0 \cdot 380$ ). The resulting model demonstrating the significant differences in the peak frequency of the two species and the negative effect of fish $L_{\mathrm{S}}$ is shown in Fig. 3, where the mean peak frequency values for each individual are also superimposed. 


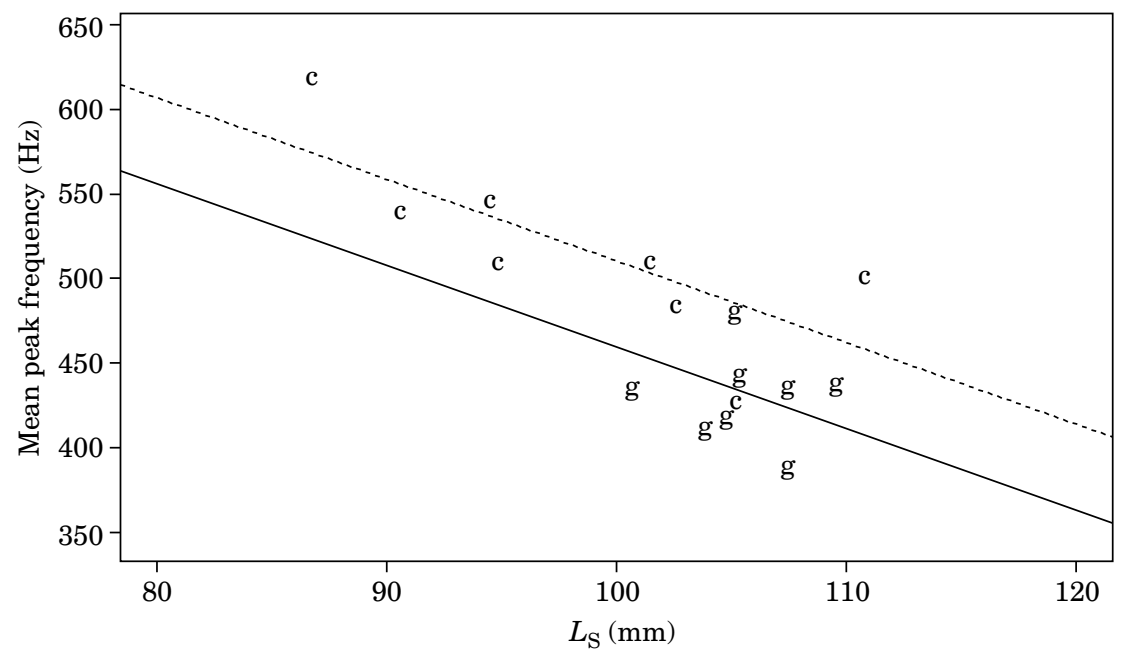

FIG. 3. Mean individual peak frequency observations in relation to fish standard length for Pseudotropheus 'zebra gold' (g) and P. callainos (c). Lines indicate LMM fit as a function of length and species (-, $P$. 'zebra gold'; ---, P. callainos) from final analysis on two species.

\section{DISCUSSION}

Males of three species of the P. zebra complex produced low frequency pulsed sounds while quivering and circling. The mean values of the recorded sound variables lay within the overall ranges expected from other studies of African mouth-brooding cichlids (Table II), although the sounds were longer in overall duration that those reported for other Malawi cichlids (Lobel, 1998).

The analysis demonstrated statistically significant differences in several properties of the sounds produced by these three closely related species. Although small sample sizes and lack of $L_{\mathrm{S}}$ data (particularly for P. zebra where reliable sound data were only available in four fish of registered length) reduced the power and scope of the analysis considering all species, the LMM results generally separated $P$. callainos from the other two species. Pseudotropheus callainos produced sounds with higher peak frequency and lower number of pulses than $P$. 'zebra gold', and of higher pulse durations than P. zebra. Marginally non-significant results also suggest that $P$. callainos sounds may have lower sound durations than $P$. 'zebra gold' and $P$. zebra. In addition, the results demonstrated that fish size $\left(L_{\mathrm{S}}\right)$ is inversely related to peak sound frequency in $P$. 'zebra gold' and $P$. callainos, thus differences in fish size should be taken into account when sound frequency properties between species are compared.

Lobel (1998) showed statistically significant differences in pulse rates and durations for two sympatric Malawian cichlids and proposed that courtship sounds could play a role in mate choice and species recognition. He also suggested that it would be worth investigating the possibility that differentiation of acoustic signals might play a role in speciation. Lobel (1998) worked on species which are not currently believed to be particularly closely related, and are placed in different genera. Thus in this study three closely related sympatric species were examined. Although the results are consistent with Lobel's (1998) 
prediction, suggesting differences between closely related species in the nature of their courtship calls, it remains to be demonstrated that females of the present study species can actually differentiate among conspecific and heterospecific males on the basis of these differences in courtship calls. Temporal discrimination has not been investigated in hearing generalists (fishes that do not possess accessory hearing structures to enhance hearing ability, in contrast with hearing specialists; Ladich \& Bass, 2003) but the plainfin midshipman fish Porichthys notatus Girard (Batrachoididae) can perceive pulse intervals as small as $10 \mathrm{~ms}$ (McKibben \& Bass, 2001) and frequency discrimination ability in hearing generalists is generally slightly $>10 \%$ difference (Fay \& Simmons, 1999) and sometimes comparable to specialists (McKibben \& Bass, 1999). Such evidence suggests that cichlids may be able to perceive the differences found among species in sound duration, number of pulses and in peak frequency, but probably not in pulse duration (Wysocki \& Ladich, 2003).

Temporal characteristics and pulse grouping patterns are believed to play a fundamental role in species recognition in fishes (Winn, 1964; Spanier, 1979; Crawford et al., 1997), although as far as is known, no one has demonstrated that courtship sounds were effective in species separation in any fish species. Equally, peak frequency is also important in animal acoustic communication and is commonly used in individual recognition and assessment in fishes (Myrberg \& Riggio, 1985; Ladich et al., 1992) and other animals (Davies \& Halliday, 1978), since it may provide information on the size of an individual. The acoustical variables that are less likely to be affected by fish morphology (e.g. body size) or environmental constraints (e.g. ambient noise and reflections) are more reliable and therefore better candidates for species recognition. As pulse duration may be affected by the signal-to noise ratio, it is suggested that the number of pulses in a sound and perhaps sound duration are good candidates for specific discrimination among the studied species. Although peak frequency is dependent on body size highly significant differences were found between $P$. 'zebra gold' and $P$. callainos for a given length, suggesting it is also a good candidate for species discrimination.

The dramatic differences in male colours among closely related species has led to an interest in the possibility that sexual selection acting on male breeding dress may have driven speciation in cichlids from Lake Malawi and elsewhere. Although the present findings are still preliminary, attention should be given to the possible role of divergent sexual selection acting on other sensory modalities, including acoustic and perhaps also olfactory stimuli produced during courtship.

MCPA thanks FCT, Portugal (grant Praxis XXI/BPD/11806/97 and pluriannual programme UI\&D 331/94) for financial support and A.D. Hawkins for advice during the early stages of this work. MEK was supported by NERC grant NER/A/S/1998/ 00011. We are especially grateful to R. Fryer for statistical help and advice. R. Robinson provided helpful comments on earlier versions of the manuscript.

\section{References}

Akamatsu, T., Okumura, T., Novarini, N. \& Yan, H. Y. (2002). Empirical refinements applicable to the recording of fish sounds in small tanks. The Journal of the Acoustical Society of America 112, 3073-3082. 
Allender, C. J., Seehausen, O., Knight, M. E., Turner, G. F. \& Maclean, N. (2003). Divergent selection during speciation of Lake Malawi cichlid fishes inferred from parallel radiations in nuptial coloration. Proceedings of the National Academy of Sciences, USA 100, 14074-14079.

Amorim, M. C. P., Fonseca, P. J. \& Almada, V. C. (2003). Sound production during courtship and spawning of the cichlid Oreochromis mossambicus: male-female and male-male interactions. Journal of Fish Biology 62, 658-672. doi: 10.1046/j.0022-1112.2003.00054.x

Baerends, G. P. \& Baerends van Roon, J. M. (1950). An introduction to the study of the ethology of cichlid fishes. Behaviour 1 (Suppl.), 1-235.

Brown, D. H. \& Marshall, J. A. (1978). Reproductive behaviour of the rainbow cichlid, Herotilapia multispinosa (Pisces, Cichlidae). Behaviour 67, 299-322.

Condé, B. \& Géry, J. (1999). Maylandia Meyer et Foerster, 1984, un nom générique disponible (Teleostei, Perciformes, Cichlidae). Revue Française d'Aquariologie et de Herpetologie 26, 21-22.

Crawford, J. D., Cook, A. P. \& Heberlein, A. S. (1997). Bioacoustic behavior of African fishes (Mormyridae): potential cues for species and individual recognition in Pollimyrus. The Journal of the Acoustical Society of America 102, 1200-1212.

Davies, N. B. \& Halliday, T. R. (1978). Deep croaks and fighting assessment in toads Bufo bufo. Nature 274, 683-685.

Dominey, W. J. (1984). Effects of sexual selection and life history on speciation: species flocks in African cichlid fish and Hawaiian Drosophila. In Evolution of Fish Species Flocks (Echelle, A. A. \& Kornfield, I., eds), pp. 231-249. Orono, ME: University of Maine Press.

Fay, R. R. \& Simmons, A. M. (1999). The sense of hearing in fishes and amphibians. In Comparative Hearing: Fish and Amphibians (Fay, R. R. \& Popper, A. N., eds), pp. 269-318. New York: Springer.

Fohrman, K. (2002). Food and feeding. In Enjoying Cichlids, 2nd edn (Konings, A., ed.), pp. 34-37. El Paso: Cichlid Press.

Jordan, R., Kellogg, K., Juanes, F. \& Stauffer, J., Jr. (2003). Evaluation of female mate choice cues in a group of Lake Malawi mbuna (Cichlidae). Copeia 2003, 181-186.

Knight, M. E. \& Turner, G. F. (1999). Reproductive isolation among closely related Lake Malawi cichlids: can males recognise conspecific females by visual cues? Animal Behaviour 58, 761-768.

Knight, M. E., Turner, G. F., Rico, C., van Oppen, M. J. H. \& Hewitt, G. M. (1998). Microsatellite paternity analysis on captive Lake Malawi cichlids supports reproductive isolation by direct mate choice. Molecular Ecology 7, 1605-1610.

Konings, A. (2002). Cichlid Fishes in their Natural Habitat, 3rd edn. El Paso: Cichlid Press.

Konstantinova, N. G., Nikol'skii, I. D. \& Termen, L. S. (1979). Acoustic and electric activity of Tilapia mossambica (Cichlidae: Pisces). Moscow University Biological Science Bulletin 34, 35-39.

Ladich, F. \& Bass, A. H. (2003). Underwater sound generation and acoustic reception in fishes with some notes on frogs. In Sensory Processing in Aquatic Environments (Collin, S. P. \& Marshall, N. J., eds), pp. 173-193. New York: Springer.

Ladich, F., Brittinger, W. \& Kratochvil, H. (1992). Significance of agonistic vocalization in the croaking gourami (Trichopsis vittatus, Teleostei). Ethology 90, 307-314.

Lobel, P. S. (1998). Possible species specific courtship sounds by two sympatric cichlid fishes in Lake Malawi, Africa. Environmental Biology of Fishes 52, 443-452.

Lobel, P. S. (2001). Acoustic behavior of cichlid fishes. Journal of Aquaculture and Aquatic Sciences 9, 167-186.

Marshall, J. A. (1971). Sound production by Tilapia mossambica (Pisces: Cichlidae). American Zoologist 11, 632.

McKibben, J. R. \& Bass, A. H. (1999). Peripheral encoding of behaviorally relevant acoustic signals in a vocal fish: single tones. Journal of Comparative Physiology A 184, 563-576.

McKibben, J. R. \& Bass, A. H. (2001). Effects of temporal envelope modulation on acoustic signal recognition in a vocal fish, the plainfin midshipman. The Journal of the Acoustical Society of America 109, 2934-2943. 
McRoberts, R. E., Brooks, R. T. \& Rogers, L. L. (1998). Using nonlinear mixed effects models to estimate size-age relationships for black bears. Canadian Journal of Zoology 76, 1098-1106.

Myrberg, A. A., Jr. \& Riggio, J. R. (1985). Acoustically mediated individual recognition by a coral reef fish (Pomacentrus partitus). Animal Behaviour 33, 411-416.

Myrberg, A. A., Jr., Spanier, E. \& Ha, S. J. (1978). Temporal patterning in acoustical communication. In Contrasts in Behaviour (Reese, E. S. \& Lighter, F. J., eds), pp 137-179. New York: John Wiley \& Sons.

Nelissen, M. (1975). Sound production by Simochromis diagramma (Günther) (Pisces, Cichlidae). Acta Zoologica et Pathologica Antverpiensia 61, 19-24.

Nelissen, M. (1977). Sound production by Haplochromis burtoni (Günther) and Tropheus moorii Boulenger (Pisces, Cichlidae). Annales de la Societe Royale Zoologique de Belgique 106, 155-166.

Nelissen, M. (1978). Sound production by some Tanganyikan cichlid fishes and a hypothesis for the evolution of the R communication mechanisms. Behaviour 64, 137-147.

van Oppen, M. J. H., Turner, G. F., Rico, C., Deutsch, J. C., Robinson, R. L., Genner, M. J. \& Hewitt, G. M. (1998). Biodiversity and evolution in rock-dwelling cichlid fishes from Lake Malawi: evidence from microsatellite markers. Molecular Ecology 7, 991-1001.

Pinheiro, J. C. \& Bates, D. M. (2000). Mixed-effects Models in S and S-PLUS. New York: Springer.

Ribbink, A. J., Marsh, B. A., Marsh, A. C., Ribbink, A. C. \& Sharp, B. J. (1983). A preliminary survey of the cichlid fishes of rocky habitats in Lake Malawi. South African Journal of Zoology 18, 149-310.

Rowland, W. J. (1978). Sound production and associated behavior in the jewel fish, Hemichromis bimaculatus. Behaviour 64, 125-136.

Seehausen, O. \& van Alphen, J. J. M. (1998). The effect of male coloration on female mate choice in closely related Lake Victoria cichlids (Haplochromis nyererei complex). Behavioral Ecology and Sociobiology 42, 1-8. doi: 10.1007/s002650050405

Spanier, E. (1979). Aspects of species recognition by sound in four species of damselfishes, genus Eupomacentrus (Pisces: Pomacentridae). Zeitschrift für Tierpsychologie 51, 301-316.

Turner, G. F. (1994). Speciation mechanisms in Lake Malawi cichlids: a critical review. In Speciation in Ancient lakes (Martens, K., Goddeeris, B. \& Coulter, G., eds), pp. 139-160. Stuttgart: Schweizerbart.

Turner, G. F. (1999). Explosive speciation of African cichlid fishes. In Evolution of Biological Diversity (Magurran, A. E. \& May, R. M., eds), pp. 217-229. Oxford: Oxford University Press.

Vodegel, N. (1978). A causal analysis of the behaviour of Pseudotropheus zebra (Boulenger) (Pisces: Cichlidae). PhD Thesis. University of Groningen, The Netherlands.

Winn, H. E. (1964). The biological significance of fish sounds. In Marine Bio-acoustics, Vol. 1 (Tavolga, W. N., ed.), pp. 213-230. Oxford: Pergamon Press.

Wysocki, L. E. \& Ladich, F. (2003). The representation of conspecifics sounds in the auditory brainstem of teleost fishes. The Journal of Experimental Biology 206, 2229-2240. 